\title{
PENGALAMAN ORANG TUA DALAM MERAWAT ANAK PENDERITA KANKER DI RUMAH HARAPAN YAYASAN VALENCIA JAKARTA
}

\author{
${ }^{1}$ Rangga Pusmaika, ${ }^{2}$ Indrayani, ${ }^{3}$ Dewi Agustin, ${ }^{4}$ Fransisca Yuniati Demang \\ ${ }^{1}$ Akbid Bina Husada Tangerang, ${ }^{2}$ STIKes Kuningan, ${ }^{3}$ Akbid Bhakti Husada Cikarang, \\ ${ }^{4}$ STIKes Santu Paulus Ruteng \\ pusmaika@gmail.com
}

\begin{abstract}
Abstrak
Kanker merupakan penyakit kronis penyebab penting kematian pada anak. Penyakit kronis yang diderita anak dalam hal ini kanker, dapat memberikan respon yang berbeda-beda pada keluarga. Penelitian ini bertujuan untuk diperolehnya informasi yang mendalam tentang pengalaman orang tua dalam merawat anak penderita kanker di Rumah Harapan Yayasan Valencia Jakarta. Metode yang digunakan adalah kualitatif, dengan Rapid Assessment Procedures (RAP). Penelitian dilakukan pada Mei 2016. Populasi penelitian seluruh orang tua yang memiliki anak penderita kanker di Rumah Harapan. Pengambilan sampel dalam penelitian ini adalah menggunakan metode purposive sampling. Hasil penelitian menunjukan selama merawat anak yang menderita kanker, orang tua mengalami stress, diperlukannya perawatan khusus bagi pasien kanker, Diperlukan adanya dukungan dalam bentuk psikososial, material dan sosial terhadap orang tua, kondisi kesehatan anak menurun merupakan hambatan terbesar bagi orang tua, diperlukan kebutuhan material dalam mendukung keperawatan, spiritual dan psikososial bagi orang tua dalam merawat anak yang menderita kanker, serta adanya harapan orang tua agar anaknya segera sembuh.
\end{abstract}

Kata Kunci $\quad$ : Kanker anak, Pengalaman, Orang tua

\section{Pendahuluan}

Saat ini, kanker menjadi penyakit serius yang mengancam kesehatan anak di dunia. Menurut Data Organisasi Kesehatan Dunia (WHO) menyebutkan setiap tahun penderita kanker di dunia bertambah 6,25 juta orang, dan dari jumlah tersebut, 4 persen atau 250 ribu penderita adalah anak-anak (YPKI, 2013). Kanker merupakan penyebab penting dari kematian anak dengan perkiraan 90.000 kematian per tahun. Setiap tahun, 
JURNAL ILMU KESEHATAN BHAKTI HUSADA:

HEALTH SCIENCES JOURNAL, VOL. 11 No. 01, JUNI 2020

DOI: 10.34305/jikbh.v11i1.149
Ciptaan disebarluaskan di bawah

Lisensi Creative Commons Atribusi-

NonKomersial-BerbagiSerupa 4.0

Internasional. diperkirakan 176.000 anak-anak yang didiagnosis dengan kanker dengan hidup mayoritas di negara berpenghasilan rendah dan menengah (LMICs). Di negara-negara berpenghasilan tinggi, kanker merupakan penyebab kedua kematian di antara anak usia 5-14 tahun setelah kecelakaan dan cedera (UICC, 2015).

Di Amerika Serikat pada tahun 2015, diperkirakan 10.380 kasus baru kanker yang didiagnosis pada anak-anak sejak lahir sampai usia 14 tahun, dan lebih dari 1.000 anak-anak akan meninggal akibat penyakit tersebut. Meskipun tingkat kematian akibat kanker pediatrik telah menurun hampir 70 persen selama empat dekade terakhir, kanker masih menjadi penyakit sebagai penyebab utama kematian di antara anak-anak. Jenis utama kanker pada anak-anak usia 0 sampai 14 tahun adalah leukemia limfositik akut (ALL), otak dan tumor lainnya sistem saraf pusat (SSP), dan neuroblastoma (NCI, 2016). Saat ini diperkirakan 2-4\% dari keseluruhan penyakit kanker di Indonesia menyerang anak-anak. Bahkan, kanker menyumbang sekitar $10 \%$ kematian pada anak-anak. Menurut data kesehatan tahun 2007, di Indonesia setiap tahun ditemukan 4.100 pasien baru kanker anak PDPERSI, (2012) di Jakarta 650 kasus baru kanker pada anak (YPKI, 2013).
Penyakit kronis yang diderita anak dalam hal ini kanker, dapat memberikan respon yang berbeda-beda pada keluarga dan hal ini dipengaruhi oleh pengalaman. Efek penyakit kanker yang diderita anak bagi orang tua menimbulkan respon psikologis yang sangat penting dikaji dan pada akhirnya secara langsung dapat mempengaruhi reaksi anggota keluarga lain dan koping anak itu sendiri (Hockenberry \& Wilson, 2018).

Nilai yang dianut keluarga dan latar belakang etnik/budaya yang berasal dari nenek moyang akan berpengaruh terhadap suatu penyakit. Keyakinan terhadap penyebab sakit dan pemeliharaan kesehatan merupakan bagian integral dari warisan budaya keluarga yang tidak bisa dipisahkan dengan keyakinan agama yang dianut. Keyakinan tentang kesehatan yang dominan diantara kebanyakan budaya adalah bahwa kesehatan berhubungan dengan kekuatan alam, kekuatan supranatural dan terjadinya ketidakseimbangan (Hockenberry \& Wilson, 2018).

Penelitian kualitatif dengan wawancara mendalam terhadap 17 keluarga tentang pengalaman kehidupan keluarga saat anak didiagnosa kanker dan temuan dari penelitian tersebut menghasilkan dua tema yakni kehidupan 
JURNAL ILMU KESEHATAN BHAKTI HUSADA:

HEALTH SCIENCES JOURNAL, VOL. 11 No. 01, JUNI 2020

DOI: 10.34305/jikbh.v11i1.149
Ciptaan disebarluaskan di bawah

Lisensi Creative Commons Atribusi-

NonKomersial-BerbagiSerupa 4.0

Internasional. yang berantakan dan berjuang untuk bertahan hidup. Ketika anak terdiagnosa kanker akan mempengaruhi kehidupan keluarga dalam waktu yang lama (Björk et al., 2005). Kehidupan keluarga yang aman digantikan oleh rasa takut, kekacauan, dan kesepian. Bjork et al., melakukan penelitian lagi mengenai pengalaman keluarga selama pengobatan kanker pada anak. Hasil penelitiannya mendapatkan enam tema, yaitu merasa lelah, mengganggu kehidupan keluarga, perasaan terpenjara dan terisolasi, mempertahankan keadaan normal, menjadi ahli dan mengubah perspektif normal (Björk et al., 2009).

Untuk mengoptimalkan pemberian pengobatan spesifik dan suportif tidak hanya melibatkan peran petugas kesehatan tetapi juga orangtua karena pemberian pengobatan spesifik dan suportif tidak hanya dilakukan di rumah sakit tetapi juga selama pasien berada di rumah atau perawatan lanjutan di rumah. Selama berada di rumah, anak dengan Kanker harus mendapat perawatan yang baik. Hal ini membutuhkan peranan yang besar dari orangtua.

Orangtua yang merawat anak dengan kanker juga dapat mempengaruhi kondisi kesehatannya karena pengobatan dan perawatan pada kanker membutuhkan waktu yang panjang dan adanya beberapa efek obat yang menimbulkan dampak pada anak misalnya obat kortikosteroid. Sebuah penelitian mengidentifikasi bahwa orang tua mengalami penurunan waktu tidur dan lamanya tidur serta kelelahan yang meningkat ketika anak menggunakan kortikosteroid dibandingkan dengan anak yang tidak menggunakan kortikosteroid. Hal ini karena kortikosteroid menyebabkan perubahan perilaku anak menjadi mudah marah dan emosi labil. Selain itu memberikan obat kemoterapi oral setiap hari selama perawatan di rumah dan menentukan waktu kunjungan kembali ke rumah sakit untuk melakukan kemoterapi lanjutan sesuai dengan protokol pengobatan merupakan stressor tersendiri bagi orangtua. Menghadapi penolakan anak untuk minum obat, dirawat kembali di rumah sakit, menolak makan, menolak istirahat, menolak menggunakan masker saat keluar rumah dan lain sebagainya (Tidwell, 2008).

Beberapa faktor berkontribusi terhadap kegagalan pengobatan diantaranya faktor ekonomi dan tingkat pendidikan. Stres yang dialami orang tua, kurangnya pengetahuan tentang efek samping pengobatan dan cara mengatasinya serta kurangnya pengalaman tentang perawatan anak juga dapat 
JURNAL ILMU KESEHATAN BHAKTI HUSADA:

HEALTH SCIENCES JOURNAL, VOL. 11 No. 01, JUNI 2020

DOI: 10.34305/jikbh.v11i1.149

berdampak pada kemampuan orangtua dalam merawat anak dengan kanker. Oleh karena itu informasi terkait pengalaman merawat dan kebutuhan informasi berdasarkan persepsi para orangtua sangat penting dalam mensukseskan tujuan asuhan.

Tujuan Penelitian ini yaitu diperolehnya informasi yang mendalam tentang pengalaman orang tua dalam merawat anaknya yang menderita kanker di Rumah Harapan Yayasan Valensia Jakarta.

\section{Metode}

Design penelitian ini adalah penelitian kualitatif dengan Rapid Assessment Procedures (RAP). Penelitian dilakukan pada Mei 2016. Populasi penelitian yaitu seluruh orang tua yang memiliki anak penderita kanker di Rumah Harapan. Pengambilan sampel menggunakan metode purposive sampling. Kriteria inklusi penelitian ini yaitu orang tua yang memiliki anak dengan penyakit kanker di Rumah Harapan Yayasan Valensia Jakarta, dengan jumlah informan 3 orang. Adapun informan kunci yaitu pengurus Rumah Harapan yang bertanggung jawab atas segala kegiatan dan keuangan Rumah Harapan. Teknik pengumpulan data penelitian ini adalah dengan wawancara mendalam kepada informan. Instrumen penelitian selain dari peneliti sendiri juga dibantu dengan instrumen berupa pedoman wawancara mendalam, lembar informed consent field notes, alat tulis dan alat perekam. Analisis data dalam penelitian ini dilakukan dengan teknik analisis isi (content analysis).

\section{HASIL DAN PEMBAHASAN}

\section{Karakteristik Partisipan}

Dalam penelitian ini jumlah partisipan sebanyak 3 orang, semua partisipan berasal dari wilayah di luar Jakarta yang saat ini tinggal sementara di rumah singgah "Rumah Harapan" agar lebih dekat dengan rumah sakit tempat anak mereka mendapatkan kemoterapi. Anak mereka di diagnosa kanker sekitar 612 bulan yang lalu. Tingkat pendidikan partisipan bervariasi, sebagian besar adalah tamat Sekolah Dasar (SD) dan satu partisipan tamat Sekolah Menengah Pertama (SMP). Pekerjaan partisipan sebagian besar adalah ibu rumah tangga dan ada satu partisipan bekerja sebagai buruh pabrik. Seluruh pasien adalah anggota BPJS sedangkan biaya hidup selama di rumah singgah sepenuhnya ditanggung oleh Rumah Harapan, sehingga keluarga tidak mengeluarkan biaya selama menjalani perawatan. 
Pengalaman orang tua merawat anak kanker di "Rumah Harapan" Yayasan Valensia Jakarta

\section{Kondisi stress orang tua terhadap keadaan anak yang menderita kanker di rumah singgah}

Hasil temuan yang teridentifikasi dalam penelitian ini terkait dengan kondisi stress atau ungkapan perasaan orang tua ketika memiliki dan merawat anak kanker di rumah singgah . meliputi perasaan sedih, cemas, panik, kecewa, bingung, seperti kesedihan:

$$
\begin{array}{lr}
\text { "sedihnya...waktu dokter } & \text { saya } \\
\text { mengatakan...anak } & \text { menderita leukemia atau kanker } \\
\text { darah..., kondisinya saat itu } & \text { sangat lemah..." (P2) }
\end{array}
$$

Sedih bu...anak saya sering rewel..dia pasti kesakitan,

"melihat anak saya sakit...rasanya sedih sekali bu.. anak saya menderita, badannya turun, cepat sakit....saya juga sedih karena dia tidak bisa bermain bebas seperti dulu lagi”, (P3)

\section{Kecemasan:}

"cemas...saya sangat cemas waktu kata dokter HB anak saya 3, harus segera di transfusi darah...waktu itu anak saya benar-benar pucat bu...saya lihat anak saya pucat sekali dan lemah" (P1)

Saya cemasnya kalo anak saya ga mau makan bu...biasanya setiap selesai di kemo..anak saya susah sekali untuk makan..dia ngeluh mual dan ga enak badan..kalo dia ga makan kan kondisi badannya juga cepat menurun bu” (P2)

Panik:

“anak saya kalo hemoglobinnya turun itu kadang keluar darah segar waktu dia $B A B$ dan kencing bu...saya panik sekali..itu biasanya kalo hemoglobinnya turun, sering juga di bibirnya ada luka lalu darahnya keluar dan berhentinya lama” (P1)

Kecewa:

"kadang kesel bu, kok anak saya ngga ada perubahan... kasihan anak saya menderita..anak saya juga sekarang sering rewel...yah karena sakitnya ini bu” (P2)

Bingung: 
JURNAL ILMU KESEHATAN BHAKTI HUSADA:

HEALTH SCIENCES JOURNAL, VOL. 11 No. 01, JUNI 2020

DOI: 10.34305/jikbh.v11i1.149

"anak saya selama sakit susah kalo disuapin makan bu...apalagi kalau baru selesai di kemoterapi, dia pasti ngga mau makan dan pengennya tiduran aja. Saya jadinya bingung bu, kan anak kanker makannya harus sehat dan teratur.. kalo dia ngga mau makan badannya juga pasti lemah" (P3)

Dalam sebuah penelitian dijelaskan bahwa orangtua yang memiliki anak dengan kanker mengalami perubahan dan permasalahan lain yang dihadapi seiring dengan perubahan yang terjadi pada anak. Kanker yang terjadi pada anak menunjukan sumber stress dan kecemasan yang ekstrim pada orangtua. Hal ini disebabkan ketakutan akan kemungkinan kematian yang terjadi pada anaknya dan dampak penyakit pada kehidupan anak (Alves et al., 2013; Hopper, 2003) Penelitian di Cina diperoleh bahwa Reaksi awal orang tua terhadap diagnosis adalah syok, penolakan, dan kekhawatiran. Namun, mereka dengan cepat menerima kenyataan dan menganggap penyakit anak mereka sebagai 'nasib' yang harus mereka terima. Mereka berkomitmen untuk merawat anak (Wong \& Chan, 2006).

\section{Kekhususan merawat anak dengan kanker di "Rumah Harapan"}

Hasil penelitian ini juga mengidentifikasi tema tentang kekhususan merawat anak dengan kanker di rumah singgah "rumah harapan”. Perawatan pasien kanker yang dilakukan partisipan selama di rumah antara lain: menjaga kebugaran tubuh anak, mencegah terjadinya infeksi, menjaga asupan nutrisi anak, dan mengurangi stres pada anak.

Menjaga kebugaran tubuh:

"Kalau jadwal istirahat...semua anak disini harus tidur siang dari jam 1 sampai jam 3 bu...dan ngga ada yang ributribut lagi, karena semua harus istirahat." (P1)

"Anak kanker harus istirahat yang cukup bu, kata dokter anak saya harus banyak istirahat, karena kondisinya masih lemah, dan tidak boleh bermain sampai kelelahan agar tidak mudah sakit." (P2)

Anak saya biasanya jam 1 udah tidur siang bu... karena disini memang ada jadwal istirahat siang, dan itu juga saran dokter." (P3) 
JURNAL ILMU KESEHATAN BHAKTI HUSADA:

HEALTH SCIENCES JOURNAL, VOL. 11 NO. 01, JUNI 2020

DOI: 10.34305/jikbh.v11i1.149

Mencegah terjadinya infeksi

"kalo keluar rumah harus pake masker bu...karena debu...apalagi di Jakarta ini kan debunya banyak bu...udaranya udah tercemar... sedangkan anak kanker daya tahan tubuhnya cepat menurun.. takutnya malah bikin cepat sakit bu. $"(P 1)$

"anak saya ngga saya kasih jajan di luar bu..kan makanan di luar belum tau bersih apa engga" (P2)

"biasanya anak saya selalu cuci tangan sebelum makan...karena udah kebiasaan makannya pake tangan. Kalo ga cuci tangan malah kotorannya bisa ikut masuk. Anak saya bisa sakit jadinya. Anak kanker kan cepat sekali turun daya tahan tubuhnya bu "(P1)

Menjaga asupan nutrisi

"selama anak saya sakit...saya selalu jaga makannya agar teratur. Makanan juga bersih dan tidak boleh yang pake baahan pengawet, yang istan, atau yg banyak micin nya. Anak
Ciptaan disebarluaskan di bawah

Lisensi Creative Commons Atribusi-

NonKomersial-BerbagiSerupa 4.0

Internasional.

saya juga saya kasih buah, karena kata dokter makan buah bagus agar anak tidak mudah kena penyakit"(p1)

"anak saya makan $3 x$ sehari dan selalu saya kasih sayur dan buah. Sejak sakit anak saya malah udah ngga pernah makan makanan yang pakai micin bu. Kalau anak saya ngga mau makan saya tetap maksa harus makan, biar dia cepat sembuhnya" (P2)

Mengurangi stress pada anak:

"anak yang sakit kanker juga harus dihibur bu...kan dia bisa stress juga karena ngga bisa main dengan teman-temannya. Tapi untungnya di rumah singgah banyak permainan juga, jadi saya sering temani anak saya menggambar. Kadang-kadang ada juga mahasiswa yang datang untuk bermain bersama anakanak disini. " (P1)

Perawatan lanjutan untuk anak dengan kanker harus diperhatikan secara khusus. Hal ini membutuhkan peranan yang besar dari orangtua karena kondisi anak dengan kanker sangat rentan terhadap sakit yang diakibatkan oleh efek samping 
JURNAL ILMU KESEHATAN BHAKTI HUSADA:

HEALTH SCIENCES JOURNAL, VOL. 11 No. 01, JUNI 2020

DOI: 10.34305/jikbh.v11i1.149

kemoterapi dan juga daya tahan tubuhnya yang lemah (Anggraini et al., 2015). Anak dengan kanker membutuhkan penanganan yang khusus karena sangat rentan terhadap terjadinya infeksi. Oleh sebab itu asupan nutrisi yang baik juga sangat penting untuk meningkatkan daya tahan tubuh anak (Tremolada et al., 2011).

\section{Memperoleh dukungan dalam} merawat anak yang menderita

\section{kanker di rumah singgah}

Sumber dukungan sosial yang diterima partisipan selama merawat anak dengan kanker di Rumah Harapan berasal dari keluarga, kelompok yang memiliki anak dengan kanker, lingkungan atau masyarakat, dan dari tenaga kesehatan.

Dukungan dari keluarga

$$
\begin{aligned}
& \text { "kalau dukungan yang pasti } \\
& \text { orang tua ya...orang tua selalu } \\
& \text { memberikan nasehat dan } \\
& \text { sering telpon. Orang tua saya } \\
& \text { di jawa." (P1) }
\end{aligned}
$$

"Suami saya selalu
mendukung... dia selalu bilang
ke saya agar tetap sabar dan
kuat...yang rawat anak-anak
dan masak dirumah selama
saya tinggal disini suami sy bu”
(P2).

Dukungan dari kelompok yang memiliki anak menderita kanker

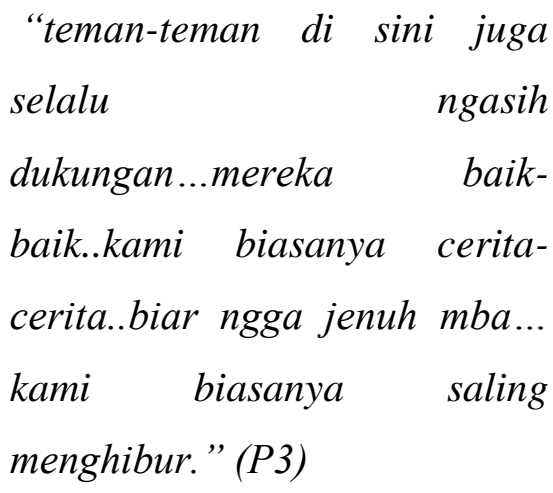

Dukungan dari lingkungan/masyarakat

"Waktu awal tahu anak saya sakit...tetangga tuh datang ke rumah terus kasi semangat bu, supaya saya sabar..."(P1)

"sama tetangga yang sering main kesini sering jenguk..sering lihatlah pengen lihat anak saya..mereka sedih juga waktu lihat anak saya sakit" (P3)

Dukungan dari tenaga kesehatan "alhamdulilah...dokter juga selalu ingatkan agar saya tetap sabar dan berdoa agar anak saya cepat sembuh bu..kata dokter anak saya harus makan teratur, jangan dikasih micin di sayur, makan buah-buahan, terus anak saya juga dapat vitamin" (P1) 
JURNAL ILMU KESEHATAN BHAKTI HUSADA:

HEALTH SCIENCES JOURNAL, VOL. 11 No. 01, JUNI 2020

DOI: 10.34305/jikbh.v11i1.149

Dukungan emosional

$\begin{array}{lrr}\text { "Kalau tetangga } & y a \\ \text { dukungannya karena } & \text { sering } \\ \text { kesini main jenguk kesini } & \text { jadikan beban kaya } n g g a \\ \text { ada..datang main itu kan jadi } \\ \text { rasanya seneng mba ditengokin } \\ \text { gitu”(P3) }\end{array}$

"suami saya selalu bilang..yang sabar.. anak-anak di rumah saya yang urus, ibu di rumah singgah aja biar fokus urus si Jeni... saya kan jadi lega mba." (P1)

Dukungan finansial

"setiap minggu kontrol ke rumah sakit bu...untung ada BPJS, jadi gratis... disini juga kita ngga bayar bu..pokoknya fokus urus anak aja, biaya makan sehari-hari semuanya dari sini. “(P1)

Alhamdulillah...saya pakai BPJS bu, jadi ga ada biaya di rumah sakit. dulu waktu tinggal di rumah sendiri susah bu..karena biaya transportnya...untung saja teman saya kasih tau kalo ada rumah singgah..jadi saya bersyukur sekali bu disini tidak ada biaya..semuanya diurus sama pengurusnya"

Dukungan informasi

"kata dokter anak saya harus makan teratur, jangan dikasih micin di sayur, makan buahbuahan, terus anak saya juga dapat vitamin" (P1)

Sebuah studi di Kenya tentang pengalaman orang tua dalam perawatan anak dengan kanker diperoleh data bahwa mayoritas orang tua saling berbagi pengalaman perawatan anak mereka di Rumah Sakit (Njuguna et al., 2015). Individu dengan sistem pendukung yang kuat akan membutuhkan intervensi yang minimum dalam menyelesaikan krisis, sedangkan individu yang tidak memiliki pendukung yang kuat akan membutuhkan intervensi yang kompleks dalam menyelesaikan krisis (Bobak et al., 2005). Ibu membutuhkan dukungan keluarga yang lain pada saat melakukan perawatan pada anak. Dukungan yang diberikan pada ibu membuat beban yang dirasakannya dapat berkurang (Anggraini et al., 2015). 
JURNAL ILMU KESEHATAN BHAKTI HUSADA:

HEALTH SCIENCES JOURNAL, VOL. 11 No. 01, JUNI 2020

DOI: 10.34305/jikbh.v11i1.149
Ciptaan disebarluaskan di bawah

Lisensi Creative Commons Atribusi-

NonKomersial-BerbagiSerupa 4.0

Internasional.
4. Hambatan dalam merawat anak yang menderita kanker di rumah singgah

Selama merawat anak yang menderita kanker di rumah singgah "Rumah Harapan" hambatan atau kesulitan yang sering dihadapi adalah anak rentan mengalami sakit. Sebagian besar partisipan mengatakan bayi sering diantar ke rumah sakit karena kondisi kesehatannya menurun. Satu partisipan lainnya mengatakan bahwa anaknya sering menangis.

"hambatannya itu pas selesai di kemoterapi...saya dan anak saya pulang kesini..eh esoknya diantar kerumah sakit lagi karena anak saya ga mau makan dan muntah...waktu itu kondisinya lemah” (P2)

"anak saya sering nangis mungkin karena ngga enak badan...jadi kadang susah juga $b u "(p 3)$

Psikologis anak penderita kanker tidak jauh berbeda dengan orang dewasa yang penderita kanker pada umumnya, yaitu mudah gelisah, tertekan, dan seringkali takut akan masa depan. Perbedaannya yaitu anak-anak cenderung diam, menutup diri dan menangis. Padahal pengaruh psikologi mempunyai dampak yang besar untuk kesehatan anak, dimana stress dapat menurunkan efektivitas kesehatan pasien. Semakin keadaanya terpuruk, stress, tertekan, kesehatannya akan semakin memburuk (Kumalasari, 2014).

\section{Kebutuhan orang tua dalam} merawat anak yang menderita kanker di rumah singgah

Kebutuhan yang diungkapkan partisipan dalam merawat anak dengan kanker di rumah antara lain kebutuhan material pendukung keperawatan, kebutuhan spiritual, dan kebutuhan psikososial.

Material pendukung perawatan anak dengan kanker

“...sebenarnya $\operatorname{sih}$ kebutuhannya itu buah buahan..yang segarsegar..sayuran sehat.. itu tiap hari mereka kan harus makan sayur dan buah" (P1)

"mainan juga penting mba... kalo ada mainan kan anak saya ngga rawel..ngga jenuh juga.. bosan kali anak 
JURNAL ILMU KESEHATAN BHAKTI HUSADA:

HEALTH SCIENCES JOURNAL, VOL. 11 No. 01, JUNI 2020

DOI: 10.34305/jikbh.v11i1.149

saya belum bisa main

keluar rumah" (P2)

"kebutuhan...yah bagusnya

kamar tidur harus bersih..

kalo bersih kan anak saya

bisa tidur nyenyak... kan

enak mba.. nyaman

rasanya." (P3)

Kebutuhan spiritual

"nomer satu yah berdoa...berdoa, tabahlah menerima...sabarlah..terus mendukung, yah itulah yang terpenting. Doa dari orang tua, dari kakak-kakaknya juga agar adeknya cepat sembuh." (P1)

Kebutuhan psikososial

“...perhatian

dari

keluarga... kakak-kakaknya juga perhatian banget...

kalo kesini ngajak adeknya cerita..terus pinter banget hibur adeknya" (P2)

Penelitian di Kenya diperoleh bahwa Perawatan kanker pada anak mengakibatkan kesulitan keuangan, orang tua mayoritas melewatkan janji pemeriksaan dengan dokter karena biaya perjalanan dan biaya rumah sakit (Njuguna et al., 2015). Studi lain menyatakan bahwa setelah 1 tahun dari diagnosis, pasien anak dengan kanker dan keluarga mereka mungkin semakin rentan terhadap tekanan keuangan terkait dengan perubahan dalam pekerjaan orang tua (Warner et al., 2015). Untuk patisipan memang menggunakan BPJS dan kebutuhan selama di Rumah Harapan dipenuhi oleh Yayasan, namun tetap ada kebutuhan penunjang lainnya yang harus dipersiapkan termasuk perubahan pekerjaan karena harus merawat anak mereka selama pengobatan dan tinggal di Rumah Harapan.

Aspek spiritual sangat penting ditekankan agar orangtua dapat memahami dan memaknai bahwa di balik cobaan penyakit memiliki hikmah kehidupan yang Diberikan oleh Tuhan Yang Maha Esa. Keikhlasan menerima penyakit merupakan modal utama munculnya motivasi, harapan dan optimisme, hal ini sesuai dengan Puchalski, (2001) yang menyatakan bahwa agama dapat meningkatkan pengendalian stress dengan mekanisme koping yang lebih baik, pasien dan keluarga yang memanfaatkan spiritual dan kepercayaan mereka dalam menghadapi penyakit, nyeri dan tekanan hidup menunjukkan bahwa mereka yang spiritual cenderung memiliki pandangan yang lebih positif dan kualitas hidup yang lebih baik. Seseorang dengan sikap keberagamaan dan kesadaran 
JURNAL ILMU KESEHATAN BHAKTI HUSADA:

HEALTH SCIENCES JOURNAL, VOL. 11 No. 01, JUNI 2020

DOI: 10.34305/jikbh.v11i1.149
Ciptaan disebarluaskan di bawah

Lisensi Creative Commons Atribusi-

NonKomersial-BerbagiSerupa 4.0

Internasional. rohaniah yang tinggi akan lebih bisa mengendalikan diri, dan bersabar, termasuk ujian sakit yang diberikan baik kepada dirinya sendiri maupun kepada keluarganya dalam hal ini yaitu anaknya (Safangatun, 2014)

Penelitian menunjukkan bahwa para ibu dari anak-anak dengan kanker, yang memerlukan perawatan di rumah sakit, memiliki kualitas hidup dan kesehatan psikologis yang lebih buruk daripada ibu-ibu dari anak-anak yang sehat (Eyigor et al., 2011; Rosenberg et al., 2014). Sehingga diperlukan dukungan psikososial yang baik karena orang tua yang mendapatkan dukungan psikososial yang tinggi dari keluarga mengurangi stress secara signifikan. Dukungan dari keluarga besar, gereja, dan profesional perawatan kesehatan diperlukan agar tetap positif selama anak mereka sakit (Brody \& Simmons, 2007).

\section{Harapan-Harapan orang tua dengan anak yang menderita kanker}

Partisipan mengungkapkan harapanharapan orang tua dalam merawat anak dengan kanker di rumah singgah "Rumah Harapan" meliputi kesembuhan anak, dukungan keluarga, memperoleh pelayanan terbaik dari tenaga kesehatan.
Kesembuhan anak

“...harapan yang paling utama semoga anak saya cepat sembuh.mba..supaya anak saya bisa main bareng temannya.dan bisa ke sekolah lagi. Anak saya udah ngga ke sekolah hamper setahun mba” (P3)

Didukung keluarga

"dari keluarga ya saya butuh dukungan dari keluarga

saya, ...untuk....merawat

anak saya biar saya semangat tetap merawat anak saya, pokoknya dukunganlah..penting dukungan..terus apa..semangat terus..." (P2) Diberi pelayanan yang baik dari tenaga kesehatan

"Pengennya ya cepat cepat kalo ada apa-apa langsung sama dokter..penginnya ya saat terjadi apa apa sama anak saya dia langsung.. periksanya jenis pelayanannya yang baik." (P2) 
JURNAL ILMU KESEHATAN BHAKTI HUSADA:

HEALTH SCIENCES JOURNAL, VOL. 11 No. 01, JUNI 2020

DOI: 10.34305/jikbh.v11i1.149

"saya pengennya selalu dapat masukan dari dokter..biar tau... setiap kontrol dokter selalu nasehatin, dokternya baik" (P3)

Hasil penelitian kualitatif yang tentang gambaran pengharapan pada ibu pada Ibu Pasien Kanker Pediatrik juga mengungkapkan harapan dan keyakinan akan kesembuhan anak (Sidabutar et al., 2012).

\section{Kesimpulan}

Semua orang tua merasakan kondisi stress ketika pertama kali mengetahui anaknya menderita penyakit kanker, kondisi khusus pada anak menyebabkan setiap anak memerlukan perawatan secara khusus terhadap anak yang menderita kanker oleh orang tua. Kondisi ini menyebabkan orang tua sangat memerlukan dukungan dalam bentuk psikososial, material dan sosial terhadap orang tua dalam merawat anaknya yang menderita kanker. Kondisi kesehatan anak menurun merupakan hambatan terbesar bagi orang tua dalam merawat anak yang menderita kanker. Diperlukan juga kebutuhan material dalam mendukung keperawatan, spiritual dan psikososial bagi orang tua dalam merawat anak yang menderita kanker. Seluruh orang tua memiliki harapan anaknya segera sembuh

\section{REFERENSI}

Alves, D. F. dos S., Guirardello, E. de B., \& Kurashima, A. Y. (2013). Stress related to care: the impact of childhood cancer on the lives of parents. Revista Latino-Americana de Enfermagem, 21(1), 356-362.

Anggraini, T. L., Rustina, Y., \& Syahreni, E. (2015). Pengalaman Orang Tua Melakukan Perawatan Lanjutan di Rumah Pada Anak Penderita Leukemia Limfoblastik Akut. JURNAL KESEHATAN BHAKTI HUSADA, 1(01), 3.

Björk, M., Wiebe, T., \& Hallström, I. (2005). Striving to survive: Families' lived experiences when a child is diagnosed with cancer. Journal of Pediatric Oncology Nursing, 22(5), 265-275.

Björk, M., Wiebe, T., \& Hallström, I. (2009). An everyday struggleSwedish families' lived experiences during a child's cancer treatment. Journal of Pediatric Nursing, 24(5), 423-432.

Bobak, I. M., Lowdermilk, D. L., \& Jensen, M. D. (2005). Keperawatan Maternitas, Edisi 4. Jakarta: EGC. 
JURNAL ILMU KESEHATAN BHAKTI HUSADA:

HEALTH SCIENCES JOURNAL, VOL. 11 No. 01, JUNI 2020

DOI: 10.34305/jikbh.v11i1.149

Brody, A. C., \& Simmons, L. A. (2007). Family resiliency during childhood cancer: The father's perspective. Journal of Pediatric Oncology Nursing, 24(3), 152-165.

Eyigor, S., Karapolat, H., Yesil, H., \& Kantar, M. (2011). The quality of life and psychological status of mothers of hospitalized pediatric oncology patients. Pediatric Hematology and Oncology, 28(5), 428-438.

Hockenberry, M. J., \& Wilson, D. (2018). Wong's nursing care of infants and children-E-book. Elsevier Health Sciences.

Hopper, G. (2003). 'Cancer and the family'. Edited by Lea Baider, Cary L. Cooper and Atara Kaplan De-Nour. Wiley, Chichester, 2000 (hardback). 572pp. ISBN: 0471803006. PsychoOncology: Journal of the Psychological, Social and Behavioral Dimensions of Cancer, 12(2), 198.

Kumalasari, L. S. (2014). Fasilitas Perawatan Anak Penderita Kanker di Surabaya. EDimensi Arsitektur Petra, 2(1), 129-134.

NCI. (2016). Chilhood Cancer. http://www.cancer.gov/types/childhoo d-cancers

Njuguna, F., Mostert, S., Seijffert, A., Musimbi, J., Langat, S., van der
Burgt, R. H. M., Skiles, J., Sitaresmi, M. N., van de Ven, P. M., \& Kaspers, G. J. L. (2015). Parental experiences of childhood cancer treatment in Kenya. Supportive Care in Cancer, 23(5), 1251-1259.

PDPERSI. (2012). Penderita Kanker adalah Anak-anak. http://www.pdpersi.co.id/content/new s.php?catid $=23 \&$ mid $=5 \&$ nid $=718$

Puchalski, C. M. (2001). The role of spirituality in health care. Baylor University Medical Center Proceedings, 14(4), 352-357.

Rosenberg, A. R., Wolfe, J., Bradford, M. C., Shaffer, M. L., Yi-Frazier, J. P., Curtis, J. R., Syrjala, K. L., \& Baker, K. S. (2014). Resilience and psychosocial outcomes in parents of children with cancer. Pediatric Blood \& Cancer, 61(3), 552-557.

Safangatun, P. (2014). Pengaruh religiusitas terhadap kesabaran (studi kasus pada orang tua pasien anak di Rumah Sakit Muhammadiyah Darul Istiqomah Kaliwungu Kendal). UIN Walisongo.

Sidabutar, F., Karli, N., \& Katagori, Y. (2012). Gambaran Pengharapan pada Ibu Pasien Kanker Pediatrik. Indonesian Journal of Cancer, 6(1).

Tidwell, J. (2008). Sleep, Fatigue and 
JURNAL ILMU KESEHATAN BHAKTI HUSADA:

HEALTH SCIENCES JOURNAL, VOL. 11 No. 01, JUNI 2020

DOI: $10.34305 /$ jikbh.v11i1.149

Caregiver Burden in Parents of Children with Acute Lymphoblastic Leukemia (ALL).

Tremolada, M., Bonichini, S., Altoè, G., Pillon, M., Carli, M., \& Weisner, T. S. (2011). Parental perceptions of health-related quality of life in children with leukemia in the second week after the diagnosis: a quantitative model. Supportive Care in Cancer, 19(5), 591-598.

UICC. (2015). Chilhood Cancer (ChiCa). http://www.uicc.org/programmes/chil dhood-cancer

Warner, E. L., Kirchhoff, A. C., Nam, G. E., \& Fluchel, M. (2015). Financial burden of pediatric cancer for patients and their families. Journal of Oncology Practice, 11(1), 12-18.

Wong, M. Y., \& Chan, S. W. (2006). The qualitative experience of Chinese parents with children diagnosed of cancer. Journal of Clinical Nursing, 15(6), 710-717.

YPKI. (2013). Kanker Pada Anak. http://ypkai.or.id/kanker-padaanak\%0A\%0A 